\title{
On the Advanced Technologies to Enhance Fisheries Production and Management
}

\section{Muruganandam $^{1 *}$, Steve R Chipps ${ }^{2}$ and PR Ojasvi ${ }^{3}$}

${ }^{1}$ Principal Scientist (Fisheries and Aquaculture), ICAR-Indian Institute of Soil and Water Conservation (ICAR-IISWC), Dehradun, India

${ }^{2}$ Professor and Unit Leader, USGS Coop. Fish and Wildlife Research Unit, South Dakota State University, Brookings, USA

${ }^{3}$ Director, ICAR-Indian Institute of Soil and Water Conservation (ICAR-IISWC), Dehradun, India

*Corresponding Author: M Muruganandam, Principal Scientist (Fisheries and Aquaculture), ICAR-Indian Institute of Soil and Water Conservation (ICAR-IISWC), Dehradun, India.

Received: June 07, 2019; Published: July 29, 2019

DOI: $10.31080 /$ ASAG.2019.03.0589

\section{Abstract}

Fisheries production in India has grown tremendously with 17 -fold increase from 0.75 million tons (mt) in $1950-51$ to $12.60 \mathrm{mt}$ in 2017-18 contributing 5.3\% to Agriculture GDP and supporting 15 million people for food and livelihoods. Yet, the progress stands at 10 times far behind the leading fish producer, the China. Owing to various constraints and for want of effective technologies and support mechanisms both the potential of fisheries and existing water resources have not been harnessed adequately. Modern and innovative technologies emerged from genetic engineering, biotechnology, molecular diagnostics, nanotechnology, Integrated Watershed Management (IWM), remote sensing, and GIS would help improve aquatic resources and fisheries production.

The IWM has emerged as one of the effective approaches of Natural Resource Management (NRM). Huge financial outlay has been earmarked annually towards various interventions of IWM like creation of water resources and Water Harvesting Structure (WHS) executed by various ministries and departments of both State and Central governments of India. Watershed-based fisheries development delves around the perspectives of soil-water conservation, river management, fisheries development, community/stakeholders participation and human resource management.

Patterns of land uses in watersheds affect downstream reaches and fisheries potential. The impacts of Land Use Land Cover Changes (LULC C) on temporal patterns in water quality and fisheries potential have been well documented. A recent study by the authors indicated that lake productivity indices including water clarity, conductivity, trophic status, and algae abundance were generally greater and altered following changes in land use patterns occurred over years. The ICAR-Indian Institute of Soil and Water Conservation (ICAR-IISWC) has been advocating watershed-based fisheries development over 20 years, and identified the needed research, policy and strategies to improve fisheries production. The experiences of ICAR-IISWC on the research, technology development, demonstration and human resource development are briefed herein.

The emerging nanotechnology revolutionizes whole food chain-from production to processing, storage, and development of innovative materials, structures, devices, products, systems and applications that exploit unique properties of nano-materials. Nanotechnologies seems to have immense application scope in almost all science and technology and environmental management including all fields of fisheries development, aquaculture production and water resource management. Nanotechnology finds uses starting from construction of WHS or ponds with relatively higher water holding or lower seepage loss, as feed ingredients, additives or nutrients towards improved feeds, appetites and feeding, modulators or carriers of medicines, drugs, vaccines and hormones towards disease prevention, detection, or cure, as water purifier, waste/resource recovery means helping water recycling, carriers of desirable genes or DNA segments towards improving breeds or strains, anti-fouling, anti-corrosive coated nets, pens, cages, rack and rafts, filters etc. with strength and tags for tagging or bar-coding and tracking of animals, fish or materials for various purposes, smart processing and packaging materials that avoid contamination and prolong shelf-life.

Keywords: Fisheries Production; ICAR-IISWC; Nanotechnology; Integrated Watershed Management (IWM); Natural Resource Management (NRM); Biotechnology; Genetic Engineering; Aquaculture 


\section{Introduction}

India being an agrarian country with over $60 \%$ people depending on agriculture for food and livelihoods, agriculture and allied sub-sectors get much importance. India with huge aquatic resources has registered a phenomenal growth in fisheries production with 12.60 million tons (mt) in 2017-18 (6.3\% of world's total fish) from mere $0.75 \mathrm{mt}$ in 1950-51, which is 17 -fold increase. Being one of the top fish producers and 2 nd in aquaculture production in world, India earns about US\$ 5.7 billion (2016-17) through exports (10\% of total export and $20 \%$ of Agriculture export). Total 42.1 lakh $t$ aquaculture produced (6.3\% of world aquaculture) and of this 95\% comes from freshwater resources. Also, fisheries sub-sector supports 15 million people for food and livelihoods and contribute $1.1 \%$ to total India's GDP (5.3\% to Agriculture GDP). Presently, freshwater fisheries is growing faster as compared to marine fisheries. About $3.58 \mathrm{mt}$ (2015-16, 33\% of total) out of estimated potential $4.41 \mathrm{mt}$ marine fish produced and rest (around $67 \%$ ) came from freshwater. Of late, aquaculture contribution outweighed capture fisheries. Despite growth, India presently produces 10 times lower quantum of fish than China (leading fish producer) and stands around 136th-rank in per capita fish consumption with only $9 \mathrm{~kg}$ amongst 160 countries of the world.

India continue to invest on research and technological advancements to improve fish production and meet projected demand $15 \mathrm{mt}$ fish by 2020 with $8 \%$ annual growth rate. Asian carps including Indian (Catla catla, Labeo rohita, Cirrhinus mrigala) and Chinese carps (Cyprinus carpio, Ctenopharyngodon idella, Hypophthalmichthys molitrix) besides catfish (Pangasius pangasius), cichlid-tilapia (Oreochromis spp.), giant prawn (Macrobrachium rosenbergii) and snakehead (Channa spp.) in warm water and trout (Salmo trutto fario, Oncorhynchus mykiss), mahseer (Tor putitora), and Indian trout (Schizothorax richardsonii) in coldwater; shrimps (Penaeus monodon, P. indicus and Litopenaeus vannamei), seabass (Lates calcarifer) in coasts and cobia (Rachycentron canadum), pompano (Trachinotus mookalee) and groupers (Epinephelus tauvina) besides oysters and seaweeds in marine environments are some of the species that are currently cultivated or promoted. Effective utilization of unutilized or under-utilized resources through modern farming systems, mobilizing farmers and other stakeholders, technological innovations and policy and support mechanisms to promote environment-friendly development are some of the ongoing thrusts on which Indian fisheries and aquaculture have focused interests. The potential of modern technologies, particularly the nanotechnologies for enhancing agriculture production and environment management have been widely documented and reviewed [1-9]. The watershed-based fisheries development and nanotechnology for the promotion of fisheries resources and production and associated environmental concerns are discussed based on existing literature.
Watershed-based fisheries development plans

The IWM begins with reconnaissance of the area, digitisation of geospatial details, planning and implementation of soil and water conservation interventions for resource management, utilisation and efficient crop, livestock and fisheries production (Photo 1). Prioritization of fisheries sensitive watersheds for regulation of fishing, stabilization of streams and rivers through various bio-engineering measures, development of situation-specific integrated farming systems, fish farming, etc. would enhance fisheries production [10-13].

Land use patterns and changes influence downstream reaches and fisheries potential. Muruganandam and Chipps [14] recently reported the association of land use pattern with water quality and fisheries potential with reference to parts of mid-west USA.Value addition to existing ponds, water harvesting structures by providing proper inlet, out let etc., production and distribution of bigger size fish seedlings for culture, networking farmers and consumers to facilitate fish farming, marketing or market development for fish production and capacity building should become thrust areas for watershed-based fisheries development.

Nanotechnological applications in fisheries and water resource management

Nanotechnology has immense scope for improving fisheries resources and production [15-22]. Natural nano-materials like nano-calcium, magnesium, selenium, calcium carbonate silica, silver, gold, zinc oxide, titanium oxides, iron oxide (magnetite), zeolite, hydrotalcite (synthetic clay mineral) etc. besides bio-based nanomaterials like nano-chitosan, iota-carrageenan, alginate, gelatin, fibers etc. extracted from plants, animals, fish and wastes or their bye-products find use variously and directly beneficial materials such as sealants, aqua-feeds or medicines besides as encapuslators, emulsifiers, suspensors, thinners, adsorbents, etc. helping delivery of interested materials, promote effective resource utilization, reduce wastes, pollution or eutrophication and help promote fisheries and water resource development. For example, nano-particles of silver (AgNPs), zinc oxide ( $\mathrm{ZnO}$ ), magnesium oxide (MgO), nano-silica (nS), aluminium oxide (Al203), titanium dioxide ( $\mathrm{TiO} 2$ ) and copper oxide ( $\mathrm{CuO}$ ) help in various bioactivities and biomodification and hence find diverse use in agriculture, fisheries, preservation and packaging of food substances and food additives, strengthening of natural fibre, removal of contaminants from soil and water bodies etc.

Nano-materials, nano-sensors, nano-particles based DNA vaccines, and gene and smart-drug delivery compounds have potentials to improve fish nutrition, production, reproduction, and prevention and treatment of diseases. Smart feeds, sealants, members, filters, absorbents, packaging materials, tags, carriers, surface 
coatings/laminates etc. are some possibilities with nano-materials. In short, promotion of human and environmental healthcare and fisheries production require prudent water management with effective water-contaminant-removal-systems and application of modern tools and technologies from bio-technology, genetic engineering, nano-technology and biopolymer-technology.
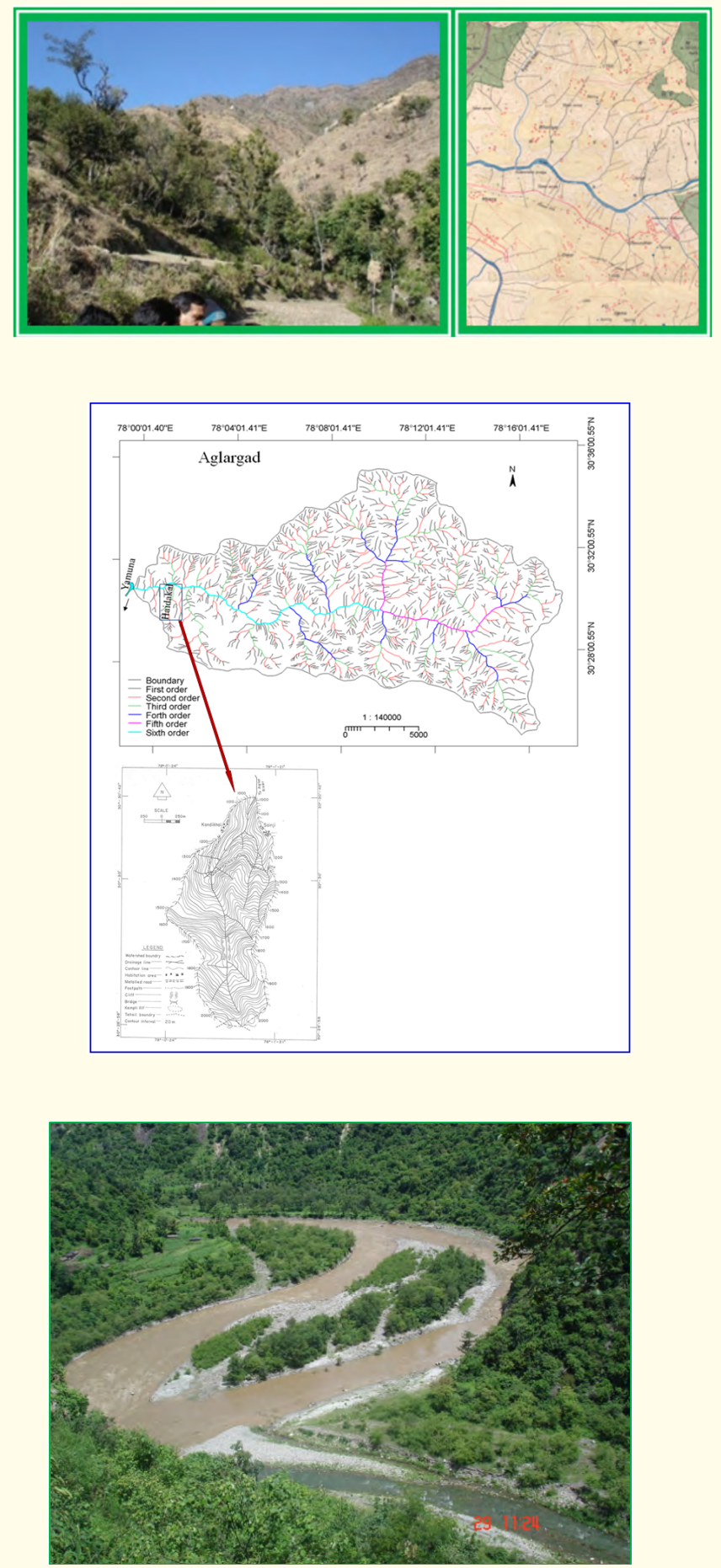
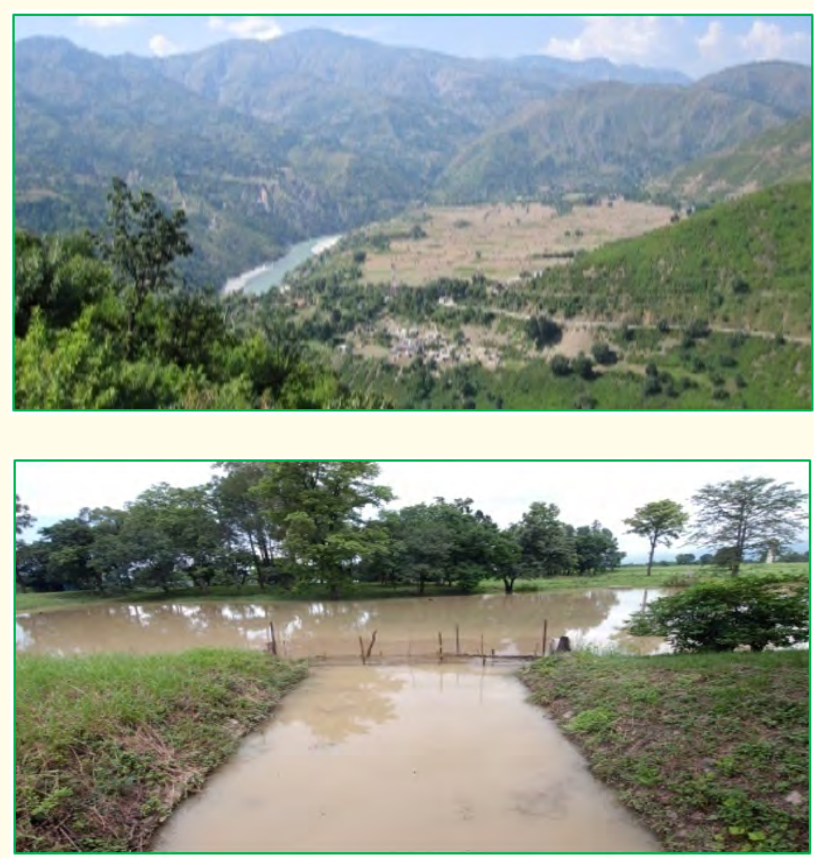

Photo 1: IWM approaches: Reconnaissance, analysis of geospatial features, drainage - line treatment and water harvesting for multiple uses.

\section{Fish feed ingredients, feed additives and feeding}

Nanotechnologies improve appetites in livestock animals, poultry birds and fish, and help increase daily weight gain, decrease feed to gain ratio, and improve overall health. Mesoporous nanosilica particles can be used for delivering fish vaccines, micronutrients and unstable ingredients through aquafeeds to fishes. Nanoencapsulation technology for fat-soluble vitamins, trace minerals, carotenoids, and fatty acids may be some examples that increase bioavailability of fast degradable micronutrients that are often less assimilated owing to poor solubility. Finding appropriate nanomaterials as feed ingredients, additives and medicine carriers like nano-particles of Selenium (Se) and calcium carbonate $\left(\mathrm{CaCO}_{3}\right)$ would provide quality feeds with appropriate physical properties (e.g. buoyancy and hardness) and help sustained release of active ingredients or medicines, minimise wastes, aquatic pollution and cost of production and thereby improve fish feeding, growth, health and overall production and economy.

\section{Fish disease surveillance and control measures}

Nano-medicines comprise nano-diagnostics, nano-vaccines, nano-therapeutics and nano-toxicological substances [23-28]. New approaches for robust fish health diagnostics even up to single virus level and delivery mechanisms especially for heat-sensitive or labile pharmaceuticals are possible with nanotechnologies. Effects of silver and zinc oxide nano-particles as promising antibacterial 
and antifungal agents against fish pathogens (bacteria, fungus, virus etc.), diagnostic and therapeutic agents have been studied extensively at various laboratories. Nano-material based solutions would effectively prevent and control diseases and pathogens and help boost aquaculture many-fold. Antibacterial or antifungal surfaces established using porous nano-structures and nano-sensors in aquaculture systems for detecting pathogens in water and nanodelivery of veterinary products and fish medicines through fish foods are some of the fish health applications of nanotechnology. Utilization rate of nano-trace elements is much higher up to $100 \%$ than that of ordinary inorganic trace elements, which is usually very limited since the former may enter animal body through direct penetration.

Some common diseases caused by virus, bacteria and fungus like Epizootic Ulcerative Syndrome (EUS) and vibriosis in fish and White-Spot Syndrome (WSS) in shrimp species take heavy toll of loss to aquaculture farmers. Controlling these diseases would require early detection and eradication of pathogens may be through nano-materials since they operate at the same scale as a virus or disease infecting particles. Chitosan-based wrap around vaccines as nano-encapsulation carrier for effective treatment delivery against bacteria and viruses that cause fish diseases have been reported since nano-encapsulated materials are sturdy and withstand high temperature or acidity. Such nano-materials become very useful in production of pathogen-free fish seedlings and shrimp or prawn post-larvae for successful farming.

\section{Fisheries and aquaculture engineering}

Nano-materials are known to give strength and longevity to various fishing crafts and gears with economic and environmental benefits. Aquaculture systems like cages, racks and rafts, pens and tanks fabricated or constructed using nano-materials are expected to have greater strength, light weights and anti-fouling or anti-corrosive features providing durability and operational ease besides environmental and economical benefits, especially when adequate demands created and supplied in large-scale. This is possible since manufactured nano-particles can also be incorporated into products in many different ways, such as surface coatings, laminates or as a material dispersed within the matrix of a product. For example, nano-surface coatings on fabrics make them water resistant, antibacterial nano-laminates on food packaging or physical structures and inclusion of nano-particles into matrix of concretes to make them resistant to saltwater erosion.

Seepage loss is the single most deterrent in porous soils where huge water loss occurs sometimes beyond water yield, rainfallrunoff or water inputs from other known sources. Developing nano-materials may be in combination with existing sealants would reduce porosity of soils that help retain water or improve water holding capacity of earthen ponds. A study by Quercia and Brouwers [29], shows light on this potential, which would allow vast extent of soils and lands that are presently unsuitable for fish farming owing to higher porosity, seepage and attendant problems of water loss, high cost of operation, poor economic returns and environmental concerns. Nano-materials like nano-silica (nS) or silica fines, zeolite and nano-clay are reported to be in use as construction material along with usual cement mortar to get strength and durability of construction. These construction materials may also find use in aquaculture systems like fishponds and tanks. Nano-materials-based pond-lining would revolutionise fish farming in most States including Himalayan States of India.

\section{Water quality management}

Nano-particles and nano-technologies help increase delivery of active ingredients from nano-capsules, nano-materials and nanoemulsion, effective adsorption/absorption of nutrients by plants and animals, reduce amount of chemicals need, and nutrient losses in fertilization and hence increase yield through better water and nutrients management. In effect, nano-fertilizers reduce leaching and excess emissions, and get incorporated into soil microorganisms on a long-term basis. Waste and pollutant adsorbents, nitrogen and phosphorus coagulants from suitable nano-materials would help improve recovery of waste water and remove nitrogen and phosphorus from rainfall runoff harvested from agricultural watersheds for reuse or productive purposes like integrated fish farming.

Biopolymer-based coagulants are known to remove nitrogen, phosphorus and most heavy metals through absorbance and the coagulated nitrogen and phosphorus may be collected and reused in agriculture fields as fertilisers benefitting both ways of improving water quality and providing economical fertiliser sources. In fact, nano-materials that help retain water or liquid, e.g. zeolites and nano-clays or soil-enhancer product based on nano-clay-particles play a vital role in retention of applied agrochemicals or liquids in soil for slow release to plants or water column in fishponds for prolonged performance. This in turn reduces nitrogen and phosphorus losses and eutrophication in associated water bodies. Removal of microbes, organic and inorganic chemicals, halogenated compounds like pesticides and heavy metals from water bodies by nano-technological applications is gaining popularity. 'Smart membranes' to remove nitrates from water has been patented by an US agency. Physical and chemical properties like surface area, hydrophilicity, thickness and charge of nano-fibers and filtrates can be suitably exploited for filteration and water retention. Positive charged nano-fibers trap negatively charged viruses and thus 
helping in their removal from farming or biological systems. The ZnO nano-particles, hydrotalcite (synthetic clay mineral), nanoscale zeolite, metal oxides, carbon nano-tubes, various noble metals (mainly as bimetallic nano-particles) and $\mathrm{TiO}_{2}$ find use in water purification, agriculture, and livestock and fisheries production.

Low-in-cost biopolymers or nano-materials could be used synergistically to remove water pollutants. Carbohydrate compounds like porous beads prepared from iota-carrageenan and alginate, seaweed polysaccharides or cereal products have potential to remove contaminants from water bodies exploiting the innate features of surface hydrology and water chemistry. The propensity of food, agricultural and industrial by-products like iota-carrageenan and alginate beads to remove nitrate and dissolved phosphorus from water resources may be studied for economically viable and technically sound technologies. The negatively charged polysaccharides, particularly, sulfate groups $\left(\mathrm{SO}_{3}^{-}\right)$of iota-carrageenan and carboxylate groups (COO-) of alginate would behave differently with the nitrates and phosphorous or other contaminants and this indeed help in removing contaminants through varying uptake kinetics.

\section{Other areas of avenues}

Fish processing, packaging and marketing industry benefits from Nanotechnology for producing quality products by timely detecting bacteria in packaging, producing strong flavour, colour quality and safety. Delivery of preferred gene or DNA into fish species for genetic improvement, better health and production as that of the possibilities presently evolved in plant nanotechnology may be a distant possibility. Use of nano materials have been reported with reference to hatchery seed production [30]. Production of nanomaterials or nano-particles from plants, fish, animals or microbes through processing of waste agricultural or animal products is yet another avenue of agricultural potential [31-33]. Nano-fibres from wheat straw and soy hulls for bio-nano composite production are examples of agri-product-based nano-materials with potential for use as fertilizers and such others. Similarly, gelatine nano-particles extracted from certain mammals and fish species may be used in encapsulating biopeptides as functional foods due to their role in preventing or delaying onset of various diseases, food fortification, improvement of food quality, increase in shelf-life, targeted peptide delivery and hence used as additives in food products.

\section{Conclusion}

The growing demand for fish and the projected demand, $15 \mathrm{mt}$ fish production by 2020 may be achieved if modern technologies are effectively harnessed and used in resource management and fisheries production. Despite huge potentials, application of watershed management principles and practices and nanotechnology in fisheries and aquaculture is continuing to be meagre. Nanotechno- logical applications in fisheries or agriculture and water management as a whole are far less prominent as compared to consumer goods and human healthcare industries. Presently minimum number of nano-products or nano-technologies only is available in the fisheries sub-sector as against huge potential. This situation provides enormous scope for allocation of enhanced financial outlays towards research and application of nanotechnologies in the sub-sector. The nano-materials and technologies may be initially cost-prohibitive, but large-scale production based on extensive demands and uses would economise ultimately.

In the face of environmental and human healthcare, use of nano-materials and technologies is not beyond risks and hazards on which presently limited knowledge exist and not understood fully that warrants categorical studies and judicious uses [34-40]. India should evolve regulations in line with many countries that have come up with regulations on use of nano-particles [41,42]. Considering potentials, Government of India had launched a Mission on Nano Science and Technology (Nano Mission) in May 2007 and a Nano Mission Council (NMC) with lead from Department of Science and Technology (DST) to promote Research on Nano-science and Technology. Also, Indian Council of Agricultural Research (ICAR) formed 'Nano-platform' to advance nanotechnology research in agriculture and allied sciences. Various Institutions and Universities in India are doing extensive research on nano-technology in line with world-wide interests on the subject, however the little. The outcomes will be known in due course of time.

\section{Bibliography}

1. Brame J., et al. "Nanotechnology enabled water treatment and reuse: emerging opportunities and challenges for developing countries". Trends in Food Science and Technology 22 (2011) 618-624.

2. Ganguly S and SK Mukhopadhayay. "Nano Science and Nanotechnology: Journey from Past to Present and Prospect in Veterinary Science and Medicine". International Journal of NanoScience and Nanotechnology 2 (2011): 79-83.

3. Handford CE., et al. "Implications of nanotechnology for the agri-food industry: Opportunities, benefits and risks". Trends in Food Science and Technology 40 (2014): 226-241.

4. Sekhon BS. "Nanotechnology in agri-food production: an overview". Nanotechnology, Science and Applications, Dovepress Review (2014): 31-53.

5. Huang S., et al. "Nanotechnology in agriculture, livestock, and aquaculture in China. A review". Agronomy for Sustainable Development 35 (2015): 369-400. 
6. Sastry KR., et al. "Nanotechnology for enhancing food security in India". Food Policy 36 (2011): 391-400.

7. Parisi C., et al. "Agricultural Nanotechnologies: What are the current possibilities?" Nano Today 10 (2015): 124-127.

8. Prasad R., et al. "Nanotechnology in Sustainable Agriculture: Recent Developments, Challenges, and Perspectives". Frontiers in Microbiology 8 (2017): 1-13.

9. Sandhya M., et al. "Integrated Approach of Agri-nanotechnology: Challenges and Future Trends". Frontiers in Plant Science (2017).

10. Muruganandam M. "Watershed-based fisheries development plans (WFDP): An overview”. Fishing Chimes 32 (2012): 41-45.

11. Muruganandam M., et al. "Watershed-based fisheries development to promote fish production in water deficient regions in India". Proceedings of the National Seminar on Development of Fisheries in Water Deficient Regions held during 25-26 February 2014 at Chennai (2014): 118-128.

12. Muruganandam M and PK Mishra. Watershed-based fisheries development: A critical analysis of a short training conducted at CSWCRTI, Dehradun: 20-24 Aug 2012. Fishing Chimes, 32.6 (2012): 12-19.

13. Muruganandam M and PK Mishra. "Watershed-based Fisheries Development: Research Initiatives and Managerial Reforms". Souvenir, 10th Indian Fisheries and Aquaculture Forum organized by Asian Fisheries Society, Indian Branch (AFSIB), Mangalore and ICAR-National Bureau of Fish Genetic Resources (NBFGR), Lucknow during 12th to 15th Nov. 2014 at Lucknow (2014): 91-102.

14. Muruganandam $M$ and Steve R Chipps. "Revisiting Natural Lakes for Water Quality Assessment and Management”. Eastern South Dakota Water Conference to be held in Brookings, SD USA on 8th Nov. 2017 (2017).

15. Ashraf M., et al. "Nanotechnology as a Novel Tool in Fisheries and Aquaculture Development: A Review". Iranica Journal of Energy and Environment 2.3 (2011): 258-261.

16. Rather MA., et al. "Nanotechnology: A Novel Tool for Aquaculture and Fisheries Development. A Prospective Mini-Review". Fisheries and Aquaculture Journal 16 (2011): 1-5.

17. Handy RD. "FSBI Briefing Paper: Nanotechnology in fisheries and aquaculture". Fisheries Society of the British Isles (2012): 1-29.
18. Helal NAS. "Nanotechnology in agriculture: A review". Agriculture and Forestry 59.1 (2013):: 117-142.

19. Bhattacharyya A., et al. "Nanotechnology: a unique future technology in aquaculture for the food security, Review". International Journal of Bioassays 4.7 (2015): 4115-4126.

20. Gehrke I., et al. "Innovations in nanotechnology for water treatment (Review)". Dovepress, open access to scientific and medical research (2015): 1-17.

21. Márquez JCM., et al. "Silver nanoparticles applications (AgNPS) in aquaculture". International Journal of Fisheries and Aquatic Studies 6 (2018): 05-11.

22. Muruganandam M., et al. "Nano-Technological Potential in Fisheries and Water Resource Management: A Review". Abstract Proceedings on the International Conference on Environmental Nanotechnology for Socio-Economic Development of India, DIT University, Dehradun (2018): 35.

23. Rajeshkumar S., et al. "Oral delivery of DNA construct using chitosan nanoparticles to protect the shrimp from white spot syndrome virus (WSSV)". Fish and Shellfish Immunology 26 (2009): 429-437.

24. Behera T and P Swain. "Antigen adsorbed calcium phosphate nanoparticles stimulate both innate and adaptive immune response in fish, Labeo rohita H". Cellular Immunology 271 (2011): 350-359.

25. Behera T and P Swain. "Antigen encapsulated alginate-coated chitosan microspheres stimulate both innate and adaptive immune responses in fish through oral immunization". Aquaculture International 22 (2014): 673-688.

26. Behera T., et al. "Nano-Fe as feed additive improves the hematological and immunological parameters of fish, Labeo rohita H". Applied Nanoscience 4 (2014): 687-694.

27. Swain P., et al. "Antimicrobial activity of metal based nanoparticles against microbes associated with diseases in aquaculture". World Journal of Microbiology and Biotechnology 30 (2014): 2491-2502.

28. Shaalan M., et al. "Recent progress in applications of nanoparticles in fish medicine: A review". Nanomedicine: Nanotechnology, Biology, and Medicine 12 (2016): 701-710.

29. Quercia G and HJH Brouwers. "Application of nano-silica (nS) in concrete mixtures". 8th fib PhD Symposium in Kgs. Lyngby, Denmark (2010): 6. 
30. Swain P., et al. "Evaluation of selected metal nanoparticles on hatching and survival of larvae and fry of Indian major carp, rohu (Labeo rohita)". Aquaculture Research 47 (2016): 498511.

31. Swain S., et al. "Green Synthesis of Gold Nanoparticles Using Root and Leaf Extracts of Vetiveria zizanioides and Cannabis sativa and its Antifungal Activities". BioNanoScience 6 (2016): 205-213.

32. Vineela D., et al. "Preparation, synthesis and characterisation of silver nanoparticles by fish scales of Catla catla and their antibacterial activity against fish pathogen, Aeromonas veronii". European Journal of Pharmaceutical and Medical Research 4 (2017): 537-545.

33. Roy S and P Anantharaman. "Biosynthesis of Silver Nanoparticles by Chlorodesmis Hildebrandtii A. Gepp and E. Gepp Including its Agricultural and Biomedical Implications". Nanomedicine and Nanotechnology Open Access (2018): 9.

34. Jovanovic B. "Immunotoxicology of titanium dioxide and hydroxylated fullerenes engineered nanoparticles in fish models". Graduate Theses and Dissertations Iowa State University Capstones, Theses and Dissertations (2011): 1-176.

35. Hedayati A., et al. "Evaluation of silver nanoparticles ecotoxicity in silver carp (Hypophthalmicthys molitrix) and goldfish (Carassius auratus)". Bulgarian Journal of Veterinary Medicine 15 (2012): 172-177.

36. Johari SA., et al. "Toxicity comparison of colloidal silver nanoparticles in various life stages of rainbow trout (Oncorhynchus mykiss)". Iranian Journal of Fisheries Sciences 12 (2013): 76-95.

37. Ostaszewska T., et al. "Histopathological effects of silver and copper nanoparticles on the epidermis, gills, and liver of Siberian sturgeon". Environmental Science and Pollution Research 23 (2016): 1621-1633.

38. Abirami T., et al. "Ecotoxicology of green synthesized silver nanoparticles on freshwater fish mystus gulio". International Journal of Pharmacy and Pharmaceutical Sciences 9.11 (2017): 192-198.

39. Mattsson K., et al. "Brain damage and behavioural disorders in fish induced by plastic nanoparticles delivered through the food chain". Scientific Reports 7 (2017): 11452.

40. Yang Y., et al. "Toxicity assessment of nanoparticles in various systems and organs (Review Open Access)". Nanotechnology Review 6 (2017): 279-289.
41. Saner M and E Heafey. "A Primer on Nanomaterials Regulation". Institute for Science, Society and Policy, University of Ottawa (2012): 1-24.

42. Glushkova A., et al. "Risk Assessment and Regulations of Nanomaterials in Norway and Russia". Norwegian Institute of Public Health (2016): 1-45.

Volume 3 Issue 8 August 2019

(C) All rights are reserved by M Muruganandam., et al. 